\title{
Steady-State Current Characteristics for Squirrel Cage Induction Motor according to Design Variables of Rotor Bars using Time Difference Finite Element Analysis
}

\author{
Young Sun Kim* \\ Department of Electrical and Electronic Engineering, Joongbu University, Goyang 10279, Korea
}

(Received 13 January 2017, Received in final form 14 February 2017, Accepted 15 February 2017)

\begin{abstract}
Induction motors have wide applicability in many fields, both in industrial sectors and households, for their advantages of a high efficiency and robust structure. The introduction of power-source-containing harmonics into the induction motor winding lowers its efficiency and increases its temperature, greatly affecting its operation characteristics. In this study, we performed an electromagnetic field analysis using the time-difference finite-element method with the purpose of analyzing the steady-state current characteristics of an induction motor. Additionally, we calculated the steady-state current with a method combining an electromagnetic field equation and a circuit equation. In the electromagnetic field analysis, the nonlinearity was taken into account using the Newton-Raphson method, and a backward time-difference method was employed for the time derivative term. Then, we compared the steady-state current of the induction motor obtained by calculation with the experimentally measured values, thus validating the proposed algorithm. Furthermore, we analyzed the impacts of the shape and material of the rotor conductor bar of the induction motor on the steady-state current of the main winding.
\end{abstract}

Keywords : finite element method, rotor slot, squirrel cage induction motor, steady-state current, time difference method

\section{Introduction}

Induction motors can be largely categorized into winding-type and squirrel-cage-type induction motors. Of these two, squirrel-cage induction motors have a wide range of application fields in industry, commerce, and households despite their moderate starting characteristics because they have excellent operating characteristics and their repairs are simple. Squirrel-cage induction motors have usually been employed for small models owing to their small starting torque with respect to the starting current. With the increasing development of large-capacity and high-efficiency motors, the demand for improving properties is becoming a pressing issue.

The steady-state analysis of electric devices using an AC generally uses a complex approximation method that postulates that the solution obtained by the electromagnetic field equation undergoes a sinusoidal variation over time. A time-difference finite-element method should be

(C)The Korean Magnetics Society. All rights reserved.

*Corresponding author: Tel: +82-31-8075-1631

Fax: +82-31-8075-1530, e-mail: yskim@joongbu.ac.kr used to accurately estimate the excess state or relative position of the slots.

In this study, design data optimized for a specific use and capacity were prepared by performing a finite-element analysis (FEA) of the steady-state current characteristics of an induction motor depending on the shape and material of the rotor conductor bar. A 2D analysis was performed under the conditions that finite-element modeling of the induction motor does not incur any changes in the system in the axial direction, and the electromagnetic field equation derived from Maxwell's equations and the stator and rotor circuit equation were combined and used for the analysis. The backward time-difference method was used for the time derivative term contained in the governing equation $[1,2]$, and the magnetic saturation of the core was reflected through a nonlinear analysis using the Newton-Raphson method [3, 4]. The rotation of the rotor was implemented by introducing moving coordinators [5], whereby the rotor was rotated at fixed intervals by inserting a slip line in the air gap [6,7], which shortened the time for element refinement by limiting it to the airgap domain.

The analysis results of the steady-state characteristics 
were validated by comparing them with the measured steady-state current of the real model, a 3-phase/4-pole/5$\mathrm{hp}$ induction motor winding, and the same algorithm was applied to the rotor slot shape and for material modification.

\section{Mathematical Algorithm}

It was postulated that the squirrel-cage induction motor had a sufficient length in the axial direction to enable a 2D analysis, and sufficient insulation was provided between the stator winding and the rotor conductor bar. Given that the stator end part and the rotor end-ring of the end parts of the induction motor in the axial direction are not included in the 2D analysis domain, the end leakage reactance $\boldsymbol{L}_{\boldsymbol{l}}$ and external circuit re were incorporated into the formula to include the end parts excluded from the 2D analysis. When performing the $2 \mathrm{D}$ analysis, the magnetic vector potential and current density are expressed by Eqs. (1) and (2), respectively.

$$
\begin{aligned}
& \mathbf{A}=A(x, y, t) \hat{a}_{z} \\
& \mathbf{J}_{\mathbf{s}}=J_{s}(x, y, t) \hat{a}_{z}
\end{aligned}
$$

The input current, which is the source term of the governing equation, is entered via the rotor winding from the external source. The external voltage source should be considered in the analysis because the current changes over time owing to the external power source and circuit impedance as the induction motor rotates. As an external circuit equation, the stator circuit equation or rotor circuit equation is combined with the electromagnetic field equation. The governing equation with the eigenvector potential $\mathrm{A}$, the winding current I, and the scalar potential differential $\nabla \varphi$ as the unknown quantity can be expressed by Eqs. (3)-(5) [2].

$$
\begin{aligned}
& \nabla^{2} \mathbf{A}-\sigma\left(\frac{\partial \mathbf{A}}{\partial t}+\nabla \varphi\right)+\mathbf{J}_{\mathbf{s}}=0 \\
& V(t)=R_{e} I(t)+L_{l} \frac{d I(t)}{d t}+N \frac{d}{d t} \oint_{c} \mathbf{A} \cdot \mathbf{d} \mathbf{l} \\
& \frac{l}{2 r_{e}}[D]^{T}[D][\nabla \varphi]+\sigma \oint_{\Omega} \frac{d A}{d t} d \Omega+\sigma \int_{\Omega} \nabla \varphi d \Omega=0
\end{aligned}
$$

Here, $\sigma$ is the conductivity of the conductor bar, $\mathbf{J}_{\mathbf{s}}$ is the current density of the winding, $R_{e}$ is the resistance of the winding, and $N$ is the number of turns of the winding. $[D]$ is the equation for the relationship between the current of the conduction bar and the end-ring current [2].

\section{Experimental Setup}

Figure 1 shows the experimental diagram, and Table 1 lists the specifications of the devices used in the experiment. Figure 2 shows the steady-state potential and current waveforms measured in a no-load experiment of the induction motor. Since an induction motor is an inductive load, the current is observed to be lagging behind the voltage.

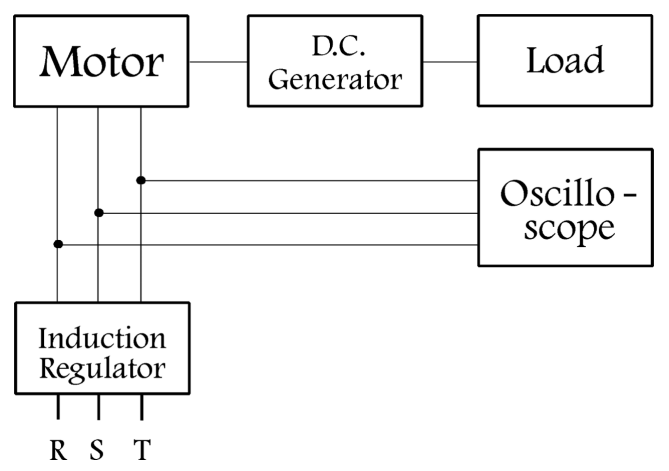

Fig. 1. Experimental diagram for measuring the voltage and current of the stator winding in the steady state.

Table 1. Specifications of the experimental device.

\begin{tabular}{ccc}
\hline \hline Equipment & Specification & Manufacturer \\
\hline $\begin{array}{c}\text { Direct Current } \\
\text { Generator }\end{array}$ & TYD-3.3 kW & $\begin{array}{l}\text { Taiyo Electric } \\
\text { Works. Japan }\end{array}$ \\
\hline A62(DC-100 Hz) & Tektronix U.S.A \\
Current Probe & 100 A Peak & \\
\hline Oscilloscope & TDS $3800 \mathrm{mV} / \mathrm{A}$ & Tektronix U.S.A \\
\hline
\end{tabular}

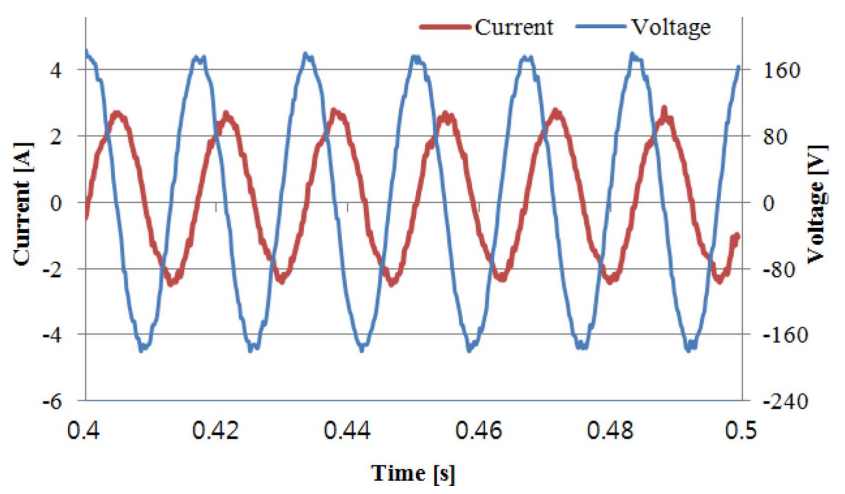

Fig. 2. (Color online) Measured voltage and current waveforms of a squirrel-cage induction motor in the steady state. 


\section{Numerical Applications}

\subsection{Reference model}

We selected a 3-phase/4-pole/5-hpinduction motor for the application of the analysis algorithm. To determine the steady-state current characteristics, an iterative analysis was performed while rotating the rotor at a predetermined speed. Taking into account the symmetry of the analysis domain, we analyzed only one quarter corresponding to one pole. At the boundary, an anti periodic boundary condition was provided in consideration of the winding

Table 2. Specifications of the analysis model.

\begin{tabular}{cccc}
\hline \hline Specification & Value & Specification & Value \\
\hline Applied voltage & $125 \mathrm{~V}$ & Frequency & $60 \mathrm{~Hz}$ \\
No. of poles & 4 & Air-gap & $0.4 \mathrm{~mm}$ \\
Dia. of stator & $190 \mathrm{~mm}$ & Winding resistance & $0.6 \Omega$ \\
No. of turns & 60 & Conductivity & $3.8 \times 10^{7} \mathrm{~S} / \mathrm{m}$ \\
\hline
\end{tabular}

distribution. Table 2 presents the specifications of the reference model. Figure 3 illustrates the distributions of the flux line depending on the analysis results for the slip.

We defined the types of rotor slots, as shown in Fig. 4, to analyze the steady-state current characteristics according to the shape and material of the rotor slots. Type 1 was defined as the closed slot in order to reduce the skin loss and pulsation loss. Types 2 and 3 were defined as open slots with shallow and deep neck lengths, respectively, thereby keeping the cross-section identical while changing the slot shape and length. Table 3 presents the electric conductivity for different rotor conduction bar materials,

Table 3. Material properties of the rotor conductor bars.

\begin{tabular}{cc}
\hline \hline Material & Conductivity $[\mathrm{S} / \mathrm{m}]$ \\
\hline Copper $(\mathrm{Cu})$ & $5.80 \times 10^{7}$ \\
Aluminum $(\mathrm{Al})$ & $3.80 \times 10^{7}$ \\
Silicon-Copper $(\mathrm{Si}-\mathrm{Cu})$ & $2.61 \times 10^{7}$ \\
\hline
\end{tabular}

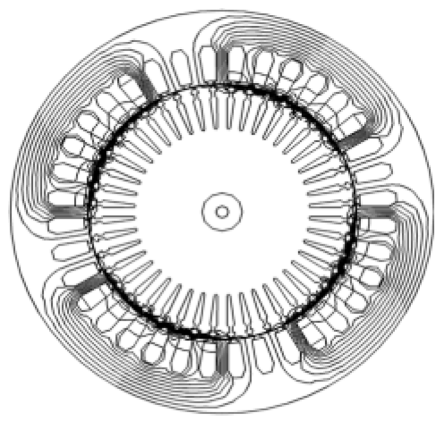

(a)

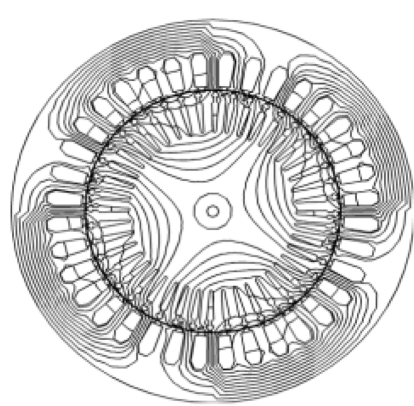

(b)

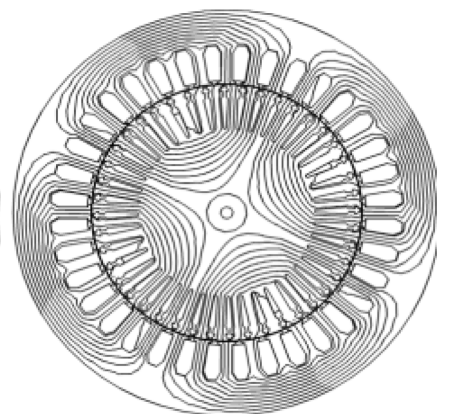

(c)

Fig. 3. Magnetic flux distributions in a 3-phase 4-pole squirrel-cage induction motor according to the slip: (a) $\mathrm{s}=0.999$, (b) $\mathrm{s}=0.9$, and $(\mathrm{c}) \mathrm{s}=0.003$.

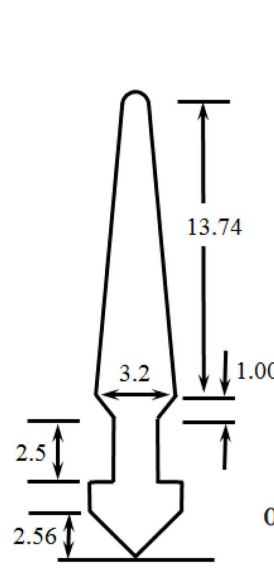

(a) Reference

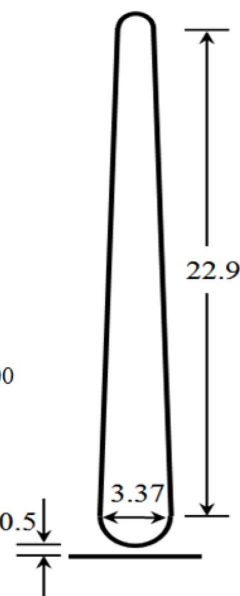

(b) Type 1

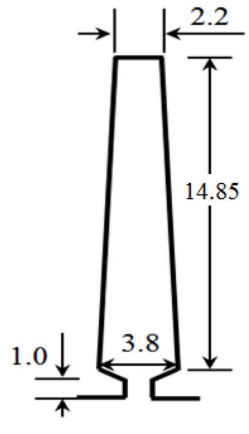

(c) Type 2

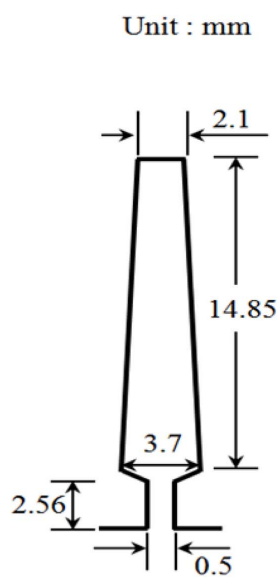

(d) Type 3

Fig. 4. Slot shape of the (a) reference model and three types of rotor bars: (b) closed slot, (c) open shallow slot, and (d) open deep slot. 
namely, copper, aluminum, and silicon-copper.

\subsection{Steady-state current characteristics}

A comparison of the results of the steady-state current simulation using the proposed algorithm and the measured values confirmed the concordance between the simulated and measured values within the error range. Figure 5 shows a comparison between the reference model simulation and the measurement results. Although the simulation yielded slightly larger values, a comparison shows that the values are nearly identical, thereby verifying the validity of the proposed algorithm. Figure 6 shows the steady-state

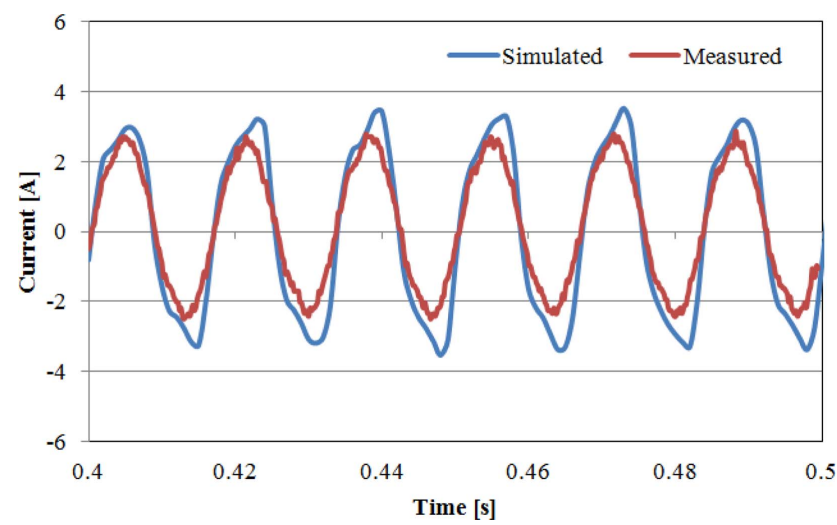

Fig. 5. (Color online) Comparison of the steady-state winding current obtained by simulation and measurement (Reference, Al).

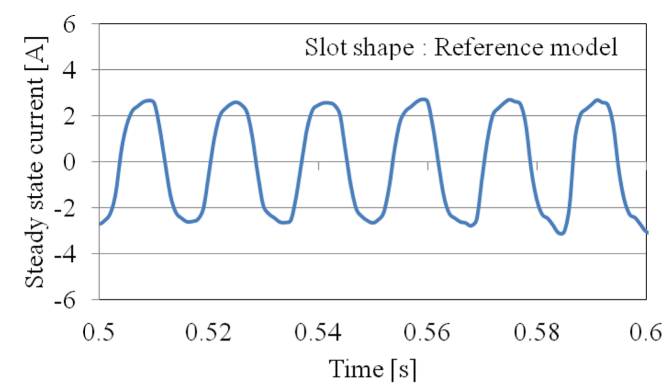

(a)

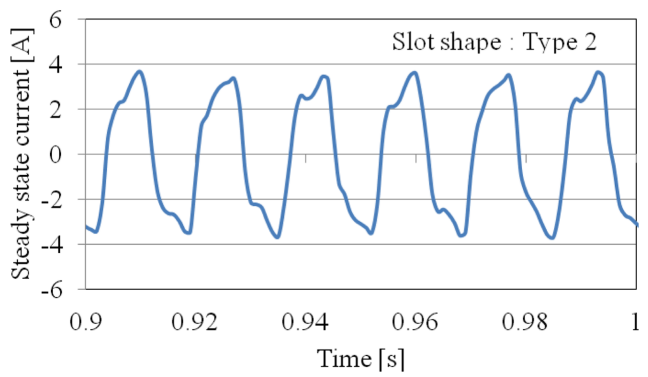

(c)

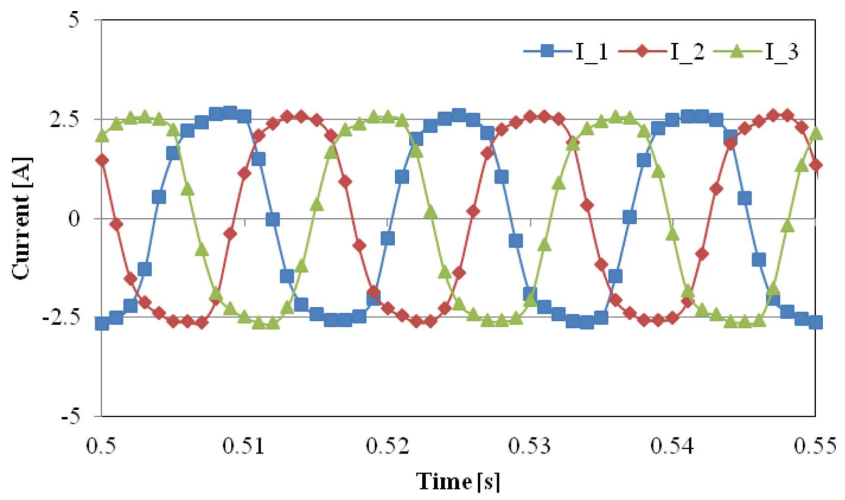

(a)

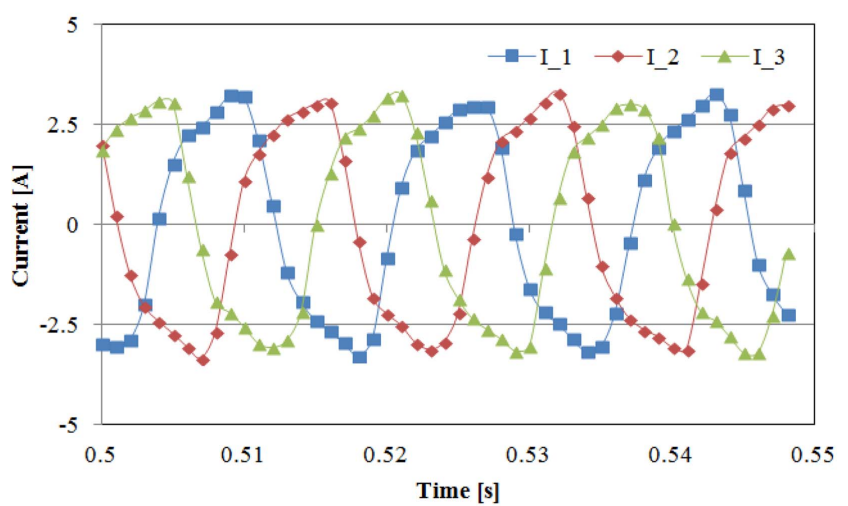

(b)

Fig. 6. (Color online) Steady-state winding current of a squirrel-cage induction motor for the reference model with (a) copper and (b) silicon-copper material.

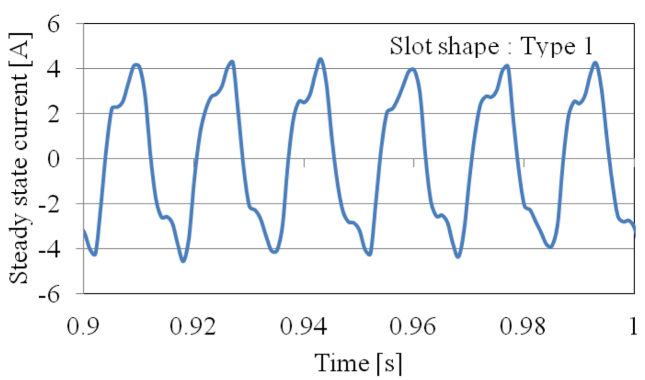

(b)

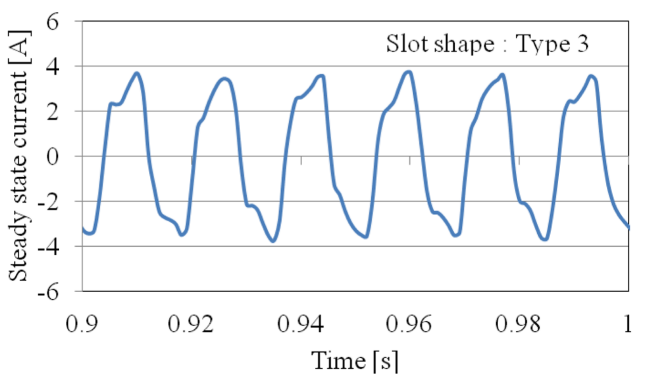

(d)

Fig. 7. (Color online) Steady-state winding current of a squirrel-cage induction motor for (a) the reference model, (b) Type 1, (c) Type 2, and (d) Type 3 (Material: Copper). 
Table 4. Steady-state current characteristics according to the rotor shape and material properties of the rotor bars.

\begin{tabular}{ccccc}
\hline \hline \multicolumn{2}{c}{ Variables } & & \multicolumn{2}{c}{ Steady-State Current [A] } \\
\cline { 1 - 2 } \cline { 5 - 5 } Shape & Material & & Max & RMS \\
\hline \multirow{3}{*}{ Reference } & $\mathrm{Al}$ & & 3.0 & 2.1 \\
& $\mathrm{Cu}$ & & 3.2 & 2.3 \\
& $\mathrm{Si}-\mathrm{Cu}$ & & 3.5 & 2.5 \\
\hline \multirow{3}{*}{ Type 1} & $\mathrm{Al}$ & & 3.8 & 2.7 \\
& $\mathrm{Cu}$ & & 4.2 & 3.0 \\
& $\mathrm{Si}-\mathrm{Cu}$ & & 4.1 & 2.9 \\
\hline \multirow{3}{*}{ Type 2} & $\mathrm{Al}$ & & 3.3 & 2.3 \\
& $\mathrm{Cu}$ & & 3.9 & 2.8 \\
& $\mathrm{Si}-\mathrm{Cu}$ & & 3.6 & 2.5 \\
\hline \multirow{2}{*}{ Type 3} & $\mathrm{Al}$ & 3.7 & 2.6 \\
& $\mathrm{Cu}$ & 4.0 & 2.8 \\
& $\mathrm{Si}-\mathrm{Cu}$ & 3.6 & 2.5 \\
\hline
\end{tabular}

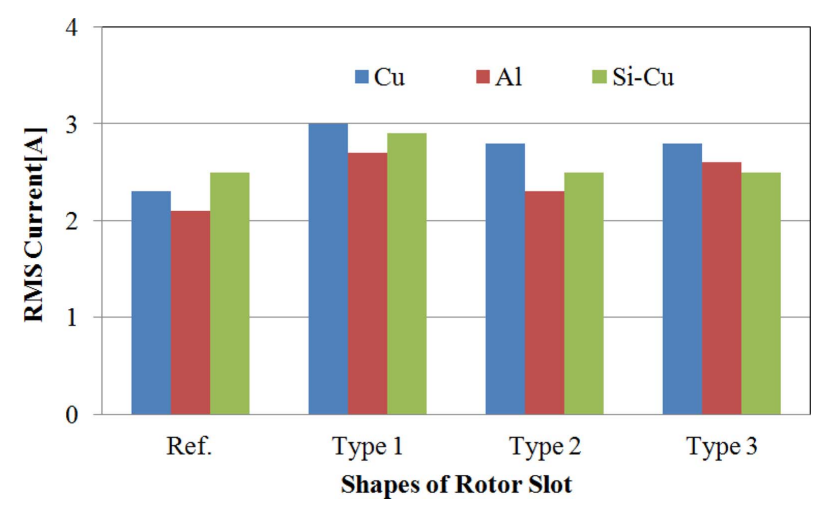

Fig. 8. (Color online) RMS values of the main winding current in the steady state according to the shape and material properties of the rotor slot.

current waveforms of the reference model with copper (top) and silicon-copper (bottom) as the conductor bar materials.

Figure 7 shows the steady-state current characteristics of the reference model with the three variations of the rotor slots. When copper was chosen as the material, the effective values of the steady-state current slightly increased for all three variations. Harmonic components were also observed in large quantities for all three slot shapes, except for the reference model.

Table 4 presents a steady-state current simulation of four rotor slot shapes and three materials, indicating the maximum and effective values of the steady-state currents. For the reference model and Types 1 and 2, the lowest steady-state current was obtained when aluminum was used as the material. For Type 3, the current increased in proportion to the conductivity of the conductor bar. Summarized results are shown in Fig. 8.

\section{Conclusion}

We introduced a time-difference finite-element method to analyze the steady-state current characteristics of a squirrel-cage induction motor. From the simulation results for different shapes and materials, no coherent patterns could be established, but the change in shape was observed to influence the steady-state current characteristics to a greater extent than the change in material. The steady current is larger than that of the reference model in the case of the close slot. The steady-state current of the motor when using copper was larger than that of other materials. The analysis method introduced in this study is considered to aid in matching the rotor slot design to its use and purpose in the induction motor design.

\section{Acknowledgment}

This work was supported by the Korea Institute of Energy Technology Evaluation and Planning (KETEP) and the Ministry of Trade, Industry \& Energy (MOTIE) of the Republic of Korea (No. 20151220200010).

\section{References}

[1] R. P. Zambrano, Transient Analysis of Induction Machines Using Finite Elements, Rensselaer Polytechnic Institute, New York (1989).

[2] H. B. Lee, Ph. D. Thesis, Seoul National University, Korea (1995).

[3] B. F. Istfan, Ph. D. Thesis, Rensselaer Polytechnic Institute, USA (1987).

[4] S. Williamson and J. W. Ralph, IEE Proc. 129, 391 (1982).

[5] K. Muramatsu, T. Nakata, N. Takahashi, and K. Fujiwara, IEEE Trans. Magn. 28, 1186 (1992).

[6] S. J. Salon and J. M. Schneider, IEEE Trans. Magn. 18, 461 (1990).

[7] F. Bouillault and A. Razek, IEEE Trans. Magn. 19, 2639 (1983). 